\title{
Relationships between Managerial Power Orientation and Unit Cohesiveness: Implications for R\&D Management at NASA
}

\author{
Augustine C. Arize ${ }^{1}$, Scott Liu ${ }^{2}$, Solomon Nyaanga ${ }^{3}$ \& John Malindretos ${ }^{4}$ \\ ${ }^{1}$ Department of Economics and Finance, Texas A\&M University, USA \\ ${ }^{2}$ Associate Dean and Director of International Programs, School of Management, New York Institute of Technology, \\ USA \\ ${ }^{3}$ Department of Marketing and Management, Cotsakos College of Business, William Paterson University, USA \\ 4 Department of Economice, Finance and Global Business, Cotsakos College of Business, William Paterson \\ University, USA \\ Correspondence: John Malindretos, Department of Economics, Finance and Global Business, Cotsakos College of \\ Business, William Paterson University, Wayne, New Jersey 07470, USA.
}

Received: July 13, 2017

Accepted: August 2, 2017

Online Published: September 13, 2017

doi:10.5430/ijba.v8n6p36

URL: https://doi.org/10.5430/ijba.v8n6p36

\begin{abstract}
This study examines relationships between managers' self and subordinate ratings of controlling and power sharing on their units' perceptions of intra-group and inter-unit cohesiveness. Four hundred and forty-five NASA middle managers and 1795 of their subordinates completed a 122 item survey of management practices and group climate. Results indicate that managers who use both controlling and power sharing behavior have more cohesive units than managers who use only one orientation. Unit cohesiveness was greater when managers' self-ratings were consistent with their subordinates' ratings.
\end{abstract}

Keywords: NASA, management control, power sharing, cohesiveness of management with subordinates

\section{Introduction}

Industrial firms today face a crisis of innovation. Recently, Abrams (1981) noted that they rely more and more on new products to generate profits and compete effectively. In high- tech environments characterized by fierce competition, economic uncertainty, and changing customers and products, there is an increasing demand for effective R\&D management.

The purpose of this study was to explore managerial behaviors that are associated with more highly cohesive work units and environments. Specifically, what type of managerial use of power is associated with better, more productive relationships within and across R\&D workgroups at NASA? A second objective was to examine the role of moderating variables such as functional specialization, managerial tenure and experience, and center mission (at NASA) on relationships between the managers' use of power and their units' cohesion.

Empirical work on leadership or managerial effectiveness has been concerned with delineating the characteristics and practices used by effective managers (Stogdil:), 1974; Bass, 1981; Campbell, Bray, etal, 1974; Dunnette, etal; 1970). However, after reviewing the plethora of studies in this field, there is not a clear, unequivocal set of skills or traits that produce more cohesive or productive workgroup performance or climates.

While effective leaders and leader behavior varies from one situation to another, the literature presents three consistent patterns of results.

First, Blake ana Mouton (1964), Lewin (Lewin, etal, 1939) and others (Fiedler, 1967, 1976; Hall, 1976; and Likert, 1967) provide evidence that leaders who are concerned with both people and production are more effective than those who focus on either people or task management. Second, McClelland (McClelland and Burnham, 1976) and others (Burke, 1981; Kotter, 1979, 1980; Tannenbaum, 1950, Boyatzias, 1982; Kipnis, 1976; 1984) indicate that the use of power or the ability to influence others is essential to group functioning and effectiveness.

Finally, researchers who have studied the functioning and management of scientists and professionals report that the effective R\&D manager is the one who can promote both independence and autonomy of thought while ensuring 
teamwork and coordination of effort between members and workgroups or units (Pelz and Andrews, 1976; Pelz, 1951, Bayton and Chapman, 1972; Andrews and Farris, 1971; Kerr and Von Glinow, 1977; McCall, 1981; Von Glinow, 1985; Holland, 1985).

Taken together, it remains unclear whether more effective leaders of research and development units are more people or task oriented or more specifically, whether their use of power is oriented towards controlling others and thereby restricting independence and ·autonomy or by exerting power "through" others or sharing their decisions and responsibilities with members of their unit.

The objective of this study is to determine if managers of more highly cohesive units are more likely to promote group effort by engaging in controlling behavior or practices (e.g. budgeting, monitoring subordinates, directing, planning, and control over costs, contractors and resources) or alternatively, by sharing power with their subordinates (e.g. involving them in decisions, delegating responsibility, rewarding participation, permitting openness, criticism, and disagreement, and encouraging autonomy). Another purpose of this study is to explore relationships between both subordinate (or unit) perceptions of the managers' use of power and the managers' self-perception of his or her own behavior and unit cohesiveness. Finally, an objective of this study is to determine whether manager or subordinate characteristics (e.g. managers' function, tenure, experience or subordinates' tenure) mediate relationships bet- ween managerial use of power and unit cohesiveness.

\section{Method}

Data were collected under NASA contract to study methods of improving management training and organizational climate. Four hundred and forty-five middle managers (GM14 and 15) and 1,795 of their subordinates were the sample in this study. To be included in this study all managers must have at least two subordinates reporting directly to them, been with NASA for two or more years, and be permanent, full-time personnel.

Subordinates of these managers were required to report directly to the manager they rated, work for NASA as full-time. employees for two or more years, occupy positions other than secretarial or clerical jobs, and agree to participate in the study. Although, managers in this study occupied over 50 different position titles, they represented four major functional groups; engineering, administration, research, and project management. Participants from 7 major NASA center locations across the United States were included in our sample. Sampling procedures were used to ensure that both basic research and applications managers were included in the study. Approximately, $30 \%$ of our sample consisted of contract, facility, operations, security, communications or public affairs managers. The other $70 \%$ were involved in managing a wide variety of tasks and activities including; space sciences, flight and fluid mechanics, propulsion and power systems, measurement and instrumentation, telemetry and guidance systems, astrophysics, astronomy, and nuclear or aerospace engineering and research.

\subsection{Subjects}

The majority of the managers in this study (66\%) worked at one of four NASA spaceflight and applications centers. The other 34\% worked at one of three research centers. Managers ranged inage from 33 to 65 years, with a mean of 48.4 years. They worked at NASA on the average for 20,6 years with a range of 2 to 39 years. Ninety percent of these managers worked for NASA for 10 or more years. Their average amount of management experience was 11.7 years. However, most (75\%) had been managers for five or more years. Of the 445 managers in our study, 428 or 97\% were males. Less than half of these managers attended NASA's Management Education Program (MEP).

Subordinates ranged in age from 23 to 67 years, with a mean age of 45.5 years. Subordinate tenure ranged from 2 to 34 years, with an average of 17.5 years. Eighty eight percent had one or more years of management experience. The amount of experience ranged from no experience to 19.5 years, with a mean of 4.3 years. The amount of time subordinates reported to their current manager ranged from 1 to 21 years, with a mean of 5.8 years. Seventy- eight percent worked for their manager for 3 or more years. One thousand five hundred and sixty-nine subordinates or $86 \%$ were males. Managerial span of control was narrow. The number of subordinates reporting to a manager ranged from 2 to 10 with a mean of 3 subordinates.

\subsection{Instruments and Procedures}

The critical incident method described by Flanagan (.19.54) and others (Burke, 1981; and Boyatzis, 1982) was used to identify a generic set of practices and skills used by NASA middle managers. A questionnaire consisting of 80 practices derived from this procedure and 42 organizational and workgroup climate items were mailed to over 600 managers and 4000 of their subordinates. The response rate for completion of this survey was $83 \%$ after turnover and attrition were computed. Response rates ranged from 67 to $89 \%$ of the eight locations in the study. 
Responses to the 80 practices were factor analyzed with verimax orthogonal rotation. Five factors that consisted of 37 items explained $67 \%$ of the variance in manager and subordinate ratings. Two of these factors were related to the managers' use of power. A six-item factor- that described behaviors concerned with monitoring people, tasks, resources, and contractors and with planning and directing was labeled "control" or "power over others". A second factor that consisted of items related to subordinate involvement, delegation, and innovation was labeled "power sharing" or "power through others". The chronbach alpha for these scales were .76 and .89 respectively. A similar procedure was used to develop two, 6-item measures of intra-group and inter-unit cohesion. Factor-analyses yielded two factors accounting for $88 \%$ of the variance in ratings of group climate. The chronback alpha's for these items were .77 and .78 respectively.

\subsection{Data Analysis Procedures}

There were three sets of independent variables in this study; subordinate (unit) ratings of managerial use of power, managers' self-ratings of power use, and an index of the degree of agreement between managers' and subordinates' ratings called the Index of Practice Agreement (IPA) score. The IPA was computed by subtracting the managers' self ratings of control and power sharing from the average rating for his or her unit. The higher the agreement between managers and subordinates the lower the IPA control and IPA power sharing scores. In order to examine the role of unit and managerial characteristics in moderating relationships between power use and group cohesiveness, seven other variables were included in our analyses. These variables were dichotomous. That is, median splits were used to divide respondents into high and low groups when the variable was continuous (e.g. tenure) rather than discrete \{e.g. center mission), The seven moderator variables entered into ANOVA were: Managers' function, center mission, managerial experience, tenure, management education, and subordinates' tenure, and years in position.

\subsection{Pre-Processing of Data}

In-order to convert individual subordinate ratings into a unit rating of score, it was necessary to develop composite scores or average scores for subordinates reporting to the same manager. Because of the small number of subordinates reporting to each manager, it was not possible to select a random or equal number of subordinates for each manager.

To get reliable data from each unit, all subordinate data were used in computing the composite or average scores. In computing managers' use of control, for example, the individual items for each subordinate were added together to form a unit practice item average. These average practices were then added together to form a unit score. Using this procedure made it possible to compute an equivalent unit score for managers with different numbers of subordinates reporting to them. A similar procedure was used to compute unit cohesiveness scores,

\section{Results}

Subordinate Ratings of Managers' Use of Power and Group Cohesion: A 2(control) X 2(power sharing) ANOVA was conducted foreach of the three measure of group cohesiveness: for all units in our sample. Significant main effects were found for both use of control and use of power sharing. These results are reported below:

\section{Intra-group Cohesiveness:}

There were significant main effects for unit ratings of control, $\mathrm{F}(1,444), 34.3$, $\mathrm{p}+. \mathrm{OOO}$, and power sharing, $\mathrm{F}(1,444)$, 83.3, $\mathrm{p}+$.OOOOl. Tukey (HSD) post hoc comparisons revealed that units that were supervised by managers who were rated highly on both controlling and power sharing behaviors had significantly better relations between members (intra-group cohesion) $(\mathrm{M}=18.66)$ compared to units supervised by managers who used only controlling behavior $(\mathrm{M}=17.22)$ or those who did not use much controlling or power sharing behavior $(\mathrm{M}=15.99) ; \mathrm{p}+.05$.

\section{Inter-Unit Cohesiveness:}

These results were similar to those reported for inter- unit cohesiveness. There were significant main effects for unit ratings of control, $\mathrm{F}(1,444), 25.8, \mathrm{p}+.0001$ and power-sharing, $\mathrm{F}\{1,444), 61.7, \mathrm{p}+.0001$. Post hoc analyses revealed that units that were supervised by managers who used both controlling and power sharing behaviors had better relations with other units $(\mathrm{N}=17.98)$ compared to managers who either used mostly control $(\mathrm{M}=16.7)$ or did not use either type of power(M=15. 7); $\mathrm{p}-+.05$.

Total Group Cohesiveness:

When unit ratings of inter- nit cohesiveness were added to intr a-group cohesiveness scores, a composite or total score was computed. These results are similar to those presented above. See Appendix Table 1 for a summary of these results. 
Functional

A 2(control) X 2(power sharing) X 4(Function) ANOVA revealed significant 2-way interactions for all 3 measures of cohesive- ness. A 2-way (control X function) interaction for intra-group cohesiveness, $\mathrm{F}(1,422), 3.1 ; \mathrm{p}+.05$ indicated that among engineering managers, units supervised by highly controlling managers had higher levels of cohesiveness and teamwork between members $(\mathrm{M}=18.2)$ compared to units supervised by managers with low use of control(M=16.8); $\mathrm{p}=+$.OS. Similar results were found for project managers. Those with high control ratings had significantly higher intra-group cohesion (M£18.2) compared to those who did not use controlling behavior $(\mathrm{M}=15.4), \mathrm{p} \cdot+.05$. There were no significant main effects or interactions for either research or administrative managers.

There was a significant 2-way (control X function) inter- action for total group cohesiveness scores, $\mathrm{F}(1,422), 3.2$; $\mathrm{p}-+.05$. Post hoc analyses indicate that among engineering managers, units that were supervised by managers who used controlling behavior had significantly higher total cohesion (within group and between units) $(\mathrm{M}=35.9)$ than managers with low control ratings (M33.3),p-+.05. Similar results were found for managers of project teams. Those with high ratings of control had more cohesive units $(\mathrm{M}=40)$ compared to those who were rated low on control( $\mathrm{M}=31.1), \mathrm{p}^{\bullet+} .01$. There was a significant 3-way interaction(control $\mathrm{X}$ power sharing $\mathrm{X}$ function) for inter unit cohesiveness, $\mathrm{F}(1,422), 2.5 ; \mathrm{p}=+$. 05. Tukey analyses revealed tha.t among engineers, managers who used both controlling and power sharing behaviors had higher unit ratings of inter-unit cohesiveness and better relations with other workgroups $(\mathrm{M}=18)$ compared to units supervised by managers who did not use controlling or power sharing behavior $(\mathrm{M}=15.8)$ or those who were highly controlling but did not share power with their subordinates $(\mathrm{M}=16.8)$; $\mathrm{p}=+.05$. Similar results were found for research managers. Research managers who used controlling behavior and shared power with their people had better relations with other research groups $(\mathrm{M}=18.5)$ compared to research managers who did not use either type of power (M-15.4or used controlling behavior without sharing power with subordinates $(M=15.4), \mathrm{p}=+.05$ There were no significant main or interaction effects for either administrators or project managers.

Management Education:

Results of a 2(control) X 2(power sharing) X 2(management education attendance) revealed significant main effects fozinter-unit , $\mathrm{F}(1,444), 10.6$, ps+.001, inter-group, $\mathrm{F}(1,444), 12.2$, $\mathrm{p}=+.001$, and total group cohesiveness, $\mathrm{F}(1,444)$, $13.5 ; \mathrm{p} \bullet+.0001$. Managers who attended a 2 -week residential training program had higher ratings of intra-, inter-, and total group cohesive- ness compare9 with those who did not attend the program. These means are presented in Table 3.

Managers' Tenure:

A 2(control) X 2(power sharing) X 2(Managers' tenure) revealed a significant main effect for inter-unit cohesiveness, $\mathrm{F}(1,444)$, 3.9, $\mathrm{p}=+. \mathrm{OS}$. Higher tenured managers (more than 20 years) had significantly higher inter-unit cohesiveness $(\mathrm{M}=17.7)$ compared to managers with less than 20 years tenure( $\mathrm{M}=16.1), \mathrm{p}-+.05$.

Managerial Experience:

A 2(control) X 2(power sharing) X 2(years in management) ANOVA indicates significant main effects for both inter-unit, $\mathrm{F}(1,444), 4.2, \mathrm{p}=+.05$, and total group cohesiveness, $\mathrm{F}(1,444), 3.9, \mathrm{p}+.05$. Units whose manager had ten or more years of _experience as a NASA manager had higher inter-unit and total cohesive- ness than those who were supervised by managers with less thanten years of experience. Means for these analyses are presented in Table 5.

Subordinates' Tenure:

ANOVA revealed significant-main effects for unit ratings of inter-unit, $F(1,444), 30.1$, intra-group, $F(1,444), 19.6$, and total group cohesiveness, $\mathrm{F}(1,444), 28.8$. These results are significant beyond the .05 level. The means in Table 6 (see appendix) indicate, units with higher-tenured subordinates (greater than 17 years) had higher unit ratings of intra-,inter, and total group cohesiveness compared to units with lower-tenured subordinates.

Managers' Self-Ratings and Group Cohesiveness:

ANOVA of managers' self-ratings of use of power sharing and control for each of the three measures of group cohesiveness did not reveal any significant main effects or interactions.

Center Mission:

There was a significant 2-way (control X center mission) interaction for inter-unit cohesiveness, F(1,418), 4.4, p-+.05. Tukey(HSD)analyses revealed that managers working at NASA's 3 basic research centers (Ames, Langley, and 
Lewis Research Centers), units who were supervised by managers who rated themselves high on control behavior had significantly better relations with other workgroups $(\mathrm{M}=17.1)$ compared with those who did not use controlling behavior $(\mathrm{M}=16.4), \mathrm{pz}+, 05$. There were no significant main effects or interactions among managers at application centers(Goddard, Johnson, Kennedy, and Marshall Space Flight Centers).

Manager-Unit Agreement and Group Cohesiveness: Inter-Unit Co siveness:

A 2(control agreement) X 2(power sharing agreement) ANOVA

for inter-unit cohesiveness scores revealed a significant main effect for power sharing agreement, $F(1,444), 45.0$, p-+.0001, Units who had a high degree of consistency and agreement between the manager and his or her subordinates' ratings of power sharing behavior had significantly better relations with other work units $(\mathrm{M}=17.5)$ compared to units in which the managers' self-ratings of power sharing exceeded those of his or her unit(M=16.3), p-+.05.

Intra-group Cohesiveness:

A 2(control agreement) X 2(power sharing agreement) ANOVA-for intra-unit cohesiveness revealed significant main effects. For both control, $\mathrm{F}(1,444), 11.3, \mathrm{p} \bullet+.001$ and power sharing agreement scores, $\mathrm{F}(1,444), 42.8, \mathrm{pz}^{+} .0001$. The mean intra-unit cohesive- ness scores of units with high manager-subordinate agreement in rating control was 17.9 compared with a mean of 16.9 for units with low manager-subordinate agreement scores. A similar pattern was found for power sharing agreement scores. Units with high manager-subordinate agreement in rating power sharing had significantly better relations within their units $(\mathrm{M}=18.2)$ compared to units in which the managers' ratings of his own power sharing behavior exceeded those of his or her subordinates(M 16.8), p-+.05.

There was a significant 2-way (control agreement $X$ power sharing agreement scores) interaction, $F(1,444)$, 5.9, $\mathrm{p}-+.02$. Units with high manager-subordinate agreement for both types of power use had significantly better relations with other units $(\mathrm{M}=18.6)$ compared to units with low agreement on both types of power behaviors $(\mathrm{M}=16.7)$ or units with high agreement on use of control but low agreement on use of power sharing behavior( $\mathrm{M}=16.9), \mathrm{p}=+.05$. This finding indicates that power sharing agreement has a more significant impact on inter-unit relations than agreement on the use of controlling behavior.

Total group cohesiveness:

As the means in Table 8 indicate, there were significant main effects for both power sharing and control agreement scores and total group cohesiveness, qonsistent with previous findings, managers' who agreed with their subordinates' ratings of both power sharing and control behaviors gad higher total group cohesiveness $(M=35.7)$ than those with low agreement on both types of power use $(\mathrm{M}=34.8)$ and units in which there was agreement in ratings of controlling behavior but low agreement in ratings of power sharing $(M=33.2)$. These 2-way interactions were significant at the .02 level, $\mathrm{F}(1,444), 3.9$.

\section{Discussion}

These data indicate that subordinates' ratings, of the control and power sharing are related to inter- and intra-group cohesion. When the manager is perceived as using both types of power, members of his or her unit perceive their unit to work better as a team and more productively with 'other groups. This finding suggests that an R\&D manager- plays two roles, One as a promoter of group efforts and the other as a controller of manpower, budgets, and resources.

These findings are consistent witb those reported by Pelz and Andrews(1976) and Andrews and Farris(1971). They suggest that effective R\&D managers must master both the project/technical side oftheir job or managing-down and the strategic/planning function-- managing laterally and upward.

These findings suggest that controlling behavior may be more important to inter-group functioning among engineering and project managers and somewhat more important to inter-unit relations for researchers and engineers. However, Additional studies would be necessary to verify such a conclusion.

Managerial tenure, experience, and subordinate tenure appear to have a positive impact on inter- and/or intra-group cohesiveness. In addition, factors involved in selecting managers for the Middle Management Education program (superior nominations or candidate decision to attend) has some impact on team perceptions of cohesivenes. This finding may be a selection artifact of those who attended the program or a consequence of attending the program or perhaps both. However, based only upon these data no firm conclusions or generalizations can be made regarding the cause of this relationship. 
Surprisingly, managers' self ratings alone were not related to their units' cohesiveness ratings. Only when center characteristics were accounted for were these ratings associated with group cohesiveness. The most interesting findings relate to consistency or agreement between managers' self-perceptions of their use of power and those of their subordinates. These data provide support for the hypothesis that there is a relationship between managersubordinate agreement and unit cohesiveness. For, when there is little difference between managers' self and subordinate (unit) ratings of either control or power sharing, group cohesiveness is higher. These data point to a critical role for subordinate perceptions of the degree to which they share power with their manager. When subordinates and managers agree on control alone, unit ratings of inter-unit and int -group cohesiveness are lower than when managers and subordinates agree in their ratings of use of power sharing.

The implications of this study are important. On the one hand, it suggests that tools that make managers of R\&D units aware of their use of power such as education programs, self-assessment, or subordinate feedback may contribute to more effective R\&D teams. Second, it suggests that factors that underlie functional, experiential or education-selection may play a role in subordinates' pescept- ions of their manager and or their unit. If these factors could be identified they might be used in the training or selection of R\&D teams or managers in organizations that are similar to NASAS. Since, this study was exploratory, additional research would be necessary to verify, clarify, or refute the findings or conclusions expressed in this paper.

\section{References}

Abrams, B. (1981, Nov.). Despite mixed record, firms still pushing for new products'. Wall Street Journal, 12.

Andrews, F., \& Farris, G. (1967). Supervisory practices and innovation in scientific teams, Personnel Psychoogy, 20, 497-515. https://doi.org/10.1111/j.1744-6570.1967.tb02446.x

Anzengruber, Johanna, et al.. (2017). Effectiveness of managerial capabilities at different hierarchical levels. Journal of Managerial Psychology, 32(2), 134-148. https://doi.org/10.1108/JMP-12-2015-0451

Ball, D., \& Donnel, M. (1979). Managerial achievement; the personal side of behavioral theory. Human Relations, 32, 77-101. https://doi.org/10.1177/001872677903200106

Bass, B. (1981). Stogdill's Handbook of Leadership. N.Y. Free Press.

Bayton, R., \& Chapman, R. (1972). Making managers of scientists and engineers. The Bureaucrat, 1(14), 407-425.

Blake, R., \& Mouton, J. (1964). The Managerial Grid. Houston: Gulf Publishing.

Bolland, F. (1985). Making Vocational Choices. Englewood Cliffs, New Jersey, Prentice-Hall.

Boyatzis, R.E. (1982). The Competent Manager. N.Y. John Wiley.

Burke, W.W., et al.. Determinants of managerial effectiveness among senior executives at NASA. Washington, D.C., NASA Technical Publication, NASW-3456.

Campbell, R., Bray, R., \& Grant, R. (1974). Formative Years in Business. N.Y., John Wiley.

Dunnette, M., et al.. (1970). Managerial Behavior, Performance, and Effectiveness. N.Y., McGraw-Hill.

Fiedler, F. (1967). A Theory of Leadership Effectiveness. N.Y., McGraw-Hill

Flanagan, J. (1954). The critical incident technique. Psychological Bulletin, 51, 327-358. https://doi.org/10.1037/h0061470

Hung, Chia-Liang. (2017). Social networks, technology ties, and gatekeeper functionality: Implications for the performance management of R\&D projects. Research Policy, 46(2017), 305-315. https://doi.org/10.1016/j.respol.2016.11.009

Kerr, S., \& Von Glinow, M. (1977). Issues in the study of organizations: The case of scientists and Engineers. Organizational Behavior Bum Perf., 18, 329-345. https://doi.org/10.1016/0030-5073(77)90034-4

Kipnis, D. (1976). The Powerholders. N.Y. Free Press.

Kipnis, D., \& Schmidt, S. (1984). Patterns of managerial influence. Organizatinal Dynamics, Winter. https://doi.org/10.1016/0090-2616(84)90025-1

Kotter, J. (1977, July/Aug.). Power, dependence and effective management. Harvard Business Review. -. (1980). Power in Management. N.Y., AMACOM.

Lewin, K., \& Lippett, G. (1939). An experimental approach to the study of autocracy and democracy. Sociometry, 1, 
292-300. https://doi.org/10.2307/2785585

Likert, R. (1967). The Human Organization. N.Y. McGraw-Hill.

McCall, M. (1981, June). Leadership and the professional Center for Creative Leadership. Technical Report, (17).

McClelland, D., \& Burnham, D. (1976). Power is the great motivator. Harvard Business Review, 54, 100-110.

Othman, Ghazala, Abdussalam Ashour Khalif, \& Ali Alammari. (2017). Human resource management: tools and strategies, 121-134.

Pelz, D.C. (1952). Influence: A key to effective leadership in the first-line supervisor. Personnel, 29, $209-217$.

Pelz, \& Andrews, F. (1976). Scientists in Organizations. N.Y., John Wiley.

Rahim, M. Afzalur. (2017). Social Intelligence, Power, and Conflict: Volume 17: Current Topics in Management. Routledge.

Stogdill, R. M. (1974). Handbook of Leadership. N.Y. Free Press.

Tannenbaum, A. (1968). Control in Organizations. N.Y., McGraw- Hil.

Von Glinow, M. (1985). Reward strategies for attracting, evaluating, and retaining professionals. Human Resource Management, 24(2), Summer, 191-206. https://doi.org/10.1002/hrm.3930240207

Wheelen, Thomas L., \& Hunger J. D. (2017). Strategic Management and Business Policy. Pearson.

Appendixes

Table 1. Mean unit cohesiveness ratings and unit ratings of managers' use of power

\begin{tabular}{|c|c|c|c|c|}
\hline $\begin{array}{l}\text { Unit Power Ratings } \\
\text { Use }\end{array}$ & & $\begin{array}{l}\text { Inter Unit } \\
\text { Cohesion }\end{array}$ & $\begin{array}{l}\text { Intra Group } \\
\text { Cohesion }\end{array}$ & $\begin{array}{l}\text { Total } \\
\text { Cohesion }\end{array}$ \\
\hline \multicolumn{5}{|l|}{ Control } \\
\hline Low & $(223)$ & $16.3 \mathrm{~b} 1 *$ & $16.7 \mathrm{~b} 2 *$ & $33.0 \mathrm{~b} 3 * *$ \\
\hline High & $(222)$ & $17.5 \mathrm{a} 1$ & $18.1 \mathrm{a} 2$ & $35.5 \mathrm{a} 3$ \\
\hline Total & $(445)$ & 16.9 & 17.4 & 34.3 \\
\hline \multicolumn{5}{|l|}{ Power Sharing } \\
\hline Low & $(223)$ & $16.1 \mathrm{~b} 1 * *$ & $16.5 \mathrm{~b} 2 * * *$ & $32.6 \mathrm{~b} 3 * * *$ \\
\hline High & $(222)$ & $17.7 \mathrm{a} 1$ & $18.4 \mathrm{a} 2$ & $36.1 \mathrm{a} 3$ \\
\hline Total & $(445)$ & 16.9 & 17.4 & 34.3 \\
\hline
\end{tabular}

a1 greater than $b 1 * \mathrm{p}=0.05$

a2 greater than $\mathrm{b} 2 * * \mathrm{p}=0.01$

a3 greater than b3 $* * * \mathrm{p}=0.001$ 
Table 2a. Mean intra-group cohesion and use of control: functional analyses

FUNCTIONAL GROUPS

\begin{tabular}{lccccc}
\hline Use of Control & Engineers & Admin. & Research & Proj. & Total \\
\hline Low & $16.8(105)$ & $16.9(39)$ & $16.7(44)$ & $15.5(24)$ & 16.7 \\
High & $* * 18.2(96)$ & $17.7(52)$ & $17.9(26)$ & $* * 18.4(37)$ & 18.0 \\
\hline Totals & $17.5(201)$ & $17.4(91)$ & $17.2(70)$ & $17.1(61)$ & 17.4 \\
\hline
\end{tabular}

Table 2b. Total cohesion and use of control: functional analyses

FUNCTIONAL GROUPS

\begin{tabular}{lrllll}
\hline Use of Control & Engineers & Admin. & Research & Proj. & Total \\
\hline & & & & & \\
Low & $33.3(105)$ & $33.0(39)$ & $32.7(44)$ & $31.0(24)$ & $33.0(212)$ \\
High & $35.9(96)$ & $34.8(52)$ & $34.8(26)$ & $36.0(37)$ & $36.0(211)$ \\
\hline Totals & $34.5(201)$ & $34.2(91)$ & $33.5(70)$ & $34.0(61)$ & 34.2 \\
\hline
\end{tabular}

Table 2c. Mean in power

FUNCTIONAL GROUPS USE OF

\begin{tabular}{|c|c|c|c|c|c|}
\hline Power & Engineers & Admin. & Research & Proj. & Tota \\
\hline Low on both types & 15.8 & 15.7 & 15.4 & 15.3 & 15.7 \\
\hline High Control & $16.8 \mathrm{~b} 1 * *$ & 16.7 & $15.4 \mathrm{~b} 2 * *$ & 17.2 & 16.7 \\
\hline High Sharing & 17.6 & 17.2 & 16.7 & 17.2 & 16.7 \\
\hline High on Both & $18.0 \mathrm{a} 1$ & 17.4 & $18.5 \mathrm{a} 2$ & 18.6 & 18 \\
\hline Totals & 17.0 & 16.8 & 16.3 & 16.9 & 16.8 \\
\hline
\end{tabular}


Tables 3-6. Mean cohesiveness ratings: Demographics

\begin{tabular}{llll}
\hline Demographic Variables & Inter Unit & Inter Group & Total \\
\hline
\end{tabular}

3) Management Education Program

\begin{tabular}{|c|c|c|c|}
\hline No ( 264) & $15.6 \mathrm{~b} 1 * *$ & $17.1 \mathrm{~b} 2 * *$ & $33.7 \mathrm{~b} 3 * * *$ \\
\hline Yes ( 181) & $17.3 \mathrm{a} 1$ & $17.9 \mathrm{a} 2$ & $35.1 \mathrm{a} 3$ \\
\hline Total ( 445) & 16.9 & 17.4 & 34.3 \\
\hline \multicolumn{4}{|c|}{$\begin{array}{l}\text { a1 greater than } \mathrm{b} 1 ; * * \mathrm{p}=0.01 \\
\mathrm{a} 2 \text { greater than } \mathrm{b} 1 ; * * * \mathrm{p}=0.001 \\
\text { a3 greater than } \mathrm{b} 3\end{array}$} \\
\hline \multicolumn{4}{|c|}{ 4) Management Tenure } \\
\hline Low (191) & $16.7 \mathrm{~b} 1$ & 17.3 & 34.1 \\
\hline High (254) & $17.0 \mathrm{a} 1$ & 17.4 & 34.1 \\
\hline Total (445) & 16.8 & 17.4 & 34.3 \\
\hline
\end{tabular}

5) Managerial Experience

\begin{tabular}{lccc} 
Low (222) & $16.8 \mathrm{~b} 1 *$ & 17.3 & $34.0 \mathrm{~b} 2$ \\
Highh (223) & $17.0 \mathrm{a} 1$ & 17.5 & $34.6 \mathrm{a} 2$ \\
\hline Total (445) & 16.9 & 17.4 & 34.3 \\
\hline
\end{tabular}

6) Mean Group Cohesiveness

\begin{tabular}{lcll} 
Low (221) & $16.4 \mathrm{~b} 1 * * *$ & $17.0 \mathrm{~b} 2 * * *$ & $33.5 \mathrm{~b} 3 * * *$ \\
High (224) & $17.3 \mathrm{a} 2$ & $17.8 \mathrm{a} 2$ & $35.1 \mathrm{a} 3$ \\
\hline Total (445) & 16.9 & 17.4 & 34.3 \\
\hline
\end{tabular}

al greater than $\mathrm{b} 1 ; * * * \mathrm{p}=0.0001$

a2 greater than $b 2$

a3 greater than b3 
Table 7. Mean inter-unit cohesion and power use: research versus applications

Center Mission

\begin{tabular}{lccc}
\hline $\begin{array}{l}\text { Managers self ratings of } \\
\text { power }\end{array}$ & Research (150) & Applications (269) & Total \\
\hline Low on Both types & $16.3 \mathrm{~b} 1^{*}$ & 17.0 & 16.8 \\
High Control & $17.2 \mathrm{a} 1$ & 16.9 & 17.0 \\
High Sharing & 16.6 & 17.3 & 17.0 \\
High on Both & 17.0 & 17.1 & 17.0 \\
\hline Total & 16.8 & 17.0 & 17.0 \\
\hline
\end{tabular}

Table 8. Mean group cohesiveness and manager- subordinate agreement

\section{COHESIVENESS}

\begin{tabular}{lccc} 
Type of Agreement & Inter Unit & Intra Group & Total \\
\hline Low on Both & $16.3 \mathrm{c} 1$ & $16.7 \mathrm{c} 2$ & $32.9 \mathrm{c3}$ \\
High $\quad$ on & $(151)$ & $(151)$ & $(151)$ \\
control and & $16.3 \mathrm{~b} 1$ & & $34.7 \mathrm{b3}$ \\
low on sharing & $(86)$ & $16.9 \mathrm{~b} 2$ & $(86)$ \\
High $\quad$ on & & $(86)$ & 33.2 \\
sharing and & 17.3 & & $(86)$ \\
low on control & $(86)$ & $(86)$ & $36.3 \mathrm{a} 3 * *$ \\
High on Both & $17.7 \mathrm{a} 1 * *$ & 17.5 & $(122)$ \\
\hline
\end{tabular}

